\title{
Effect of glochidia infection on growth of fish: freshwater pearl mussel Margaritifera margaritifera and brown trout Salmo trutta
}

\author{
M. Motiur R. Chowdhury (D) Timo J. Marjomäki · Jouni Taskinen
}

Received: 13 November 2018/Revised: 9 May 2019/Accepted: 11 June 2019/Published online: 30 July 2019

(C) The Author(s) 2019

\begin{abstract}
Effect of freshwater mussels' (Unionoida) glochidia on the growth of fish host has remained poorly studied. We compared the specific growth rate of the juvenile, PIT-marked brown trout (Salmo trutta) between uninfected controls to those experimentally infected (average initial intensity of infection 8000 fish $^{-1}$ ) with Margaritifera margaritifera glochidia, kept in high and low feeding. Growth and mortality of fish were monitored for 10 months. Our hypothesis was that glochidiosis would impair the growth of fish. According to our hypothesis, infected fish gained statistically significantly less weight than the control fish throughout the experiment. A proportional increase in weight of control individuals was $11 \%$ higher than that of the infected fish. However, neither the feeding regime (high, low) nor the period (September-November, November-March, MarchMay), had a significant effect on the growth difference between control and infected fish. As the effect of infection on the growth of fish was subtle and no effect on host mortality was detected either, this may turn
\end{abstract}

Guest editors: Manuel P. M. Lopes-Lima, Nicoletta Riccardi, Maria Urbanska \& Ronaldo G. Sousa / Biology and Conservation of Freshwater Molluscs

M. M. R. Chowdhury $(\bowtie) \cdot$ T. J. Marjomäki .

J. Taskinen

Department of Biological and Environmental Science,

University of Jyväskylä, P.O. Box 35, 40014 Jyväskylä,

Finland

e-mail: motiur.chowdhury@jyu.fi public opinion favorable for $M$. margaritifera conservation even if the salmonid host population is important for commercial or recreational fishing.

Keywords Bivalvia $\cdot$ Conservation $\cdot$ Endangered species $\cdot$ Host-parasite relationship $\cdot$ Salmonidae . Unionoida

\section{Introduction}

Although the relationship between glochidium larvae of freshwater mussels Unionoida and their obligatory fish hosts has been frequently described as phoretic commensalism (glochidia benefit from transportation services by fish, with no harm to fish) (Modesto et al., 2018) or even symbiotic (both partners benefit; Ziuganov, 2005), increasing evidence has accumulated that the relationship is actually parasitic. Stable isotope analysis, during the glochidial attachment to the fish host, indicating acquirement of nutrients from the fish (Fritts et al., 2013; Denic et al., 2015). Heavy glochidia load can induce mortality of fish, indicating clear harm to the fish host (Taeubert and Geist, 2013). When infected with glochidia, fish host develops acquired immunity, indicating activation of the immune system because of the attached glochidia (Bauer and Vogel, 1987; Rogers-Lowery et al., 2007; Chowdhury et al., 2017). 
Consequently, several adverse effects of glochidiosis on fish host have been reported, including, for example, energetic cost and dysfunction of liver, kidneys and gills (Slavik et al., 2017), altered behavior (Horky et al., 2014; Terui et al., 2017) and reduced expression of secondary sexual traits and decreased sperm quality (Kekäläinen et al., 2014).

These negative effects of glochidia can be expected to reduce the fitness of the fish host, thereby suggesting the role of freshwater mussels (glochidia) as a selective force and emphasizing the possibility of mussel-fish coevolution. Indeed, the recent findings of population-specific adaptations of mussels to infect certain host species or local fish host (Salonen et al., 2017; Douda et al., 2017b) support the view of (antagonistic) co-evolution between mussels and their fish hosts. In addition, these adverse effects may turn public opinion against the restoration of disappeared mussel populations if the fish host is an important target for commercial or recreational fisheries.

However, to date, the possible negative impact of freshwater mussels on one of the main fitness components, the growth of the fish host, has not been clearly shown except one invasive mussel species Sinanodonta woodiana Lea 1834 (Douda et al., 2017a). Treasurer et al. (2006) observed no significant effect of M. margaritifera Linnaeus 1758 infection on the growth of Atlantic salmon (Salmo salar Linnaeus 1758) in the initial stage of the parasitic period but a negative effect at 15 weeks which disappeared by the end of the 1-y monitoring period. In a study on another margaritiferid, M. laevis Haas 1910, no effect on the growth of the salmonid host Oncorhynchus masou masou Brevoort 1856 was found during the first 50 days of infection, but a negative impact was observed after the detachment of M. laevis glochidia at 70 days post-infection (Ooue et al., 2017). To our knowledge, these are the only studies focusing on the possible effects of freshwater mussels Margaritifera spp. on the growth of their fish hosts.

Therefore, the objective of the current study was to examine the effect of glochidia infection on the growth of the fish host. Brown trout (S. trutta Linnaeus 1758) and freshwater pearl mussel $M$. margaritifera were chosen because of the exceptionally long parasitic period of M. margaritifera - up to 11 months (Hastie \& Young, 2001; Salonen \& Taskinen, 2017)—should enhance the detection of growth-effect as compared to mussel species with a short parasitic period. In addition, $M$. margaritifera is one of the few unionoids that grow remarkably in size during their parasitic period. Glochidia of $M$. margaritifera multifold their size while attached to the gills of the fish host (Young \& Williams, 1984; Bauer \& Vogel, 1987; Salonen et al., 2017), which should intensify the possible growth-effect of glochidia on the host. Moreover, this methodology was chosen since it was possible to have mussel-host association where the suitability of host has been verified and where the mussel population used is specialized to infect exactly the fish host used. Results of Salonen et al. (2016) show that brown trout is a suitable host for M. margaritifera, and the $M$. margaritifera population utilized in the present study, sourced from the River Jukuanoja, is adapted to use exclusively brown trout as the fish host species (Salonen et al., 2017).

Margaritifera margaritifera is an endangered species (e.g., Geist, 2010; Lopes-Lima et al., 2017; Oulasvirta et al., 2017) whose glochidia are produced in captive breeding programmes using brown trout as fish host (e.g., Buddensiek, 1995; Thomas et al., 2010; Gum et al., 2011; Eybe et al., 2015; Moorkens, 2018). One-way to strengthen declining $M$. margaritifera populations - or to restore the extinct populationswould be to stock juvenile brown trout infected with M. margaritifera glochidia to the target rivers (Wellmann, 1943; Buddensiek, 1995; Geist et al. 2006; Thomas et al., 2010; Sousa et al., 2013, 2015, 2018). This is a realistic, though little utilized option in $M$. margaritifera areas where juvenile salmonids are stocked, either for recreational fishing purposes or to strengthen the salmonid populations, and where conditions for completion of the life cycle of M. margaritifera are otherwise favorable, like in northern Fennoscandia. If $M$. margaritifera glochidia do not impair the growth of brown trout, or if the growtheffects of $M$. margaritifera infection are negligible, this might encourage landowners, fishing managers, fishing right owners' associations and salmonid conservation programmes to use glochidia-infected juvenile Salmo spp. in their stockings. The question of whether dietary limitation upon the fish host could enhance the possible growth-effect of glochidia on fish is also interesting because the breeding programmes of M. margaritifera require feeding of the fish host in captivity, even though feeding opportunities of fish hosts are variable in natural conditions. Therefore, the current study varied experimental conditions by 
applying two food levels, high- and low-feeding regimes, to study the interaction between the possible growth-effect of $M$. margaritifera and feeding of the fish host.

A number of negative effects of $M$. margaritifera on its fish host have been described. M. margaritifera glochidia cause hyperplasia and fusion of gill filaments (Treasurer \& Turnbull, 2000; Thomas et al., 2014), inhibit swimming capability and increase mortality (Taeubert \& Geist, 2013), reduce foraging, activity and dominance success (Österling et al., 2014; Filipsson et al., 2016), induce spleen enlargement and lessen mucous cells of gills (Thomas et al., 2014) and increase metabolic rate and level of hematocrit (Filipsson et al., 2017). Therefore, our hypothesis was that $M$. margaritifera glochidia infection is harmful, decreasing the growth of the fish host, brown trout. In addition, we also hypothesized that the negative growth-effect of glochidia would be more pronounced in fish receiving less food.

\section{Materials and methods}

The experiment was conducted at the Konnevesi Research Station, University of Jyväskylä. On 31th August 2015, brown trout (age group $1+$ year, originating from Laukaa fish farm of the Natural Resources Institute Finland) were exposed to $M$. margaritifera glochidia, collected on the same day from the River Jukuanoja, a tributary of the River Iijoki, northern Finland (for map, see Salonen \& Taskinen, 2017). The glochidia of $M$. margaritifera were collected by a non-destructive method (Young $\&$ Williams, 1984; Bauer \& Vogel, 1987; Salonen et al., 2016; Chowdhury et al., 2017) where 30 gravid mussels were placed into 51 of plastic buckets with the 31 of river water for $30 \mathrm{~min}$ on the day of infection. The timing of the glochidia release in the River Jukuanoja was based on the previous knowledge that was at the end of August (Chowdhury et al., 2017; Salonen \& Taskinen, 2017) to ensure the fully matured glochidia. After incubation, the gravid mussels were returned to the river. The collected glochidial suspension was facilitated with aeration and additional water. In addition, the temperature of the glochidial suspension was kept low $\left(4-6^{\circ} \mathrm{C}\right)$ to maintain the viability of glochidia during the transportation using ice bag in the insulated box. The number of juveniles and viability was counted per ml of glochidial suspension, which was 1190 , and $95 \%$, respectively. Fish were transported to the research station 2 weeks before exposure and randomly allocated into two 1631 flow-through tanks. Exposure was performed in one of the tanks with $14.3 \times 10^{5}$ glochidia for $1.5 \mathrm{~h}$, at a temperature of $16.8^{\circ} \mathrm{C}$. During the exposure, water volume was reduced to 701 , water flow stopped, and aeration provided. Control fish in the other tank was treated in a similar way except they were exposed to lake water without glochidia. Fish had not been exposed earlier to M. margaritifera or any other glochidia in the fish farm.

A subsample of fish from both the infected and control group was killed to check the success of glochidial infection 3 days post-exposure. The infection was highly successful in the glochidia-exposed fish, among which the average ( \pm SE) number of glochidia was $7889 \pm 390 \mathrm{fish}^{-1}$ individual $(n=3)$, or $138 \pm 3$ glochidia $\mathrm{g}^{-1}$ of fish, whereas no glochidia were found in the control group $(n=3)$.

On the12th September 2015, all the fish were marked individually with PIT (passive integrated transponder, $7 \times 1.35 \mathrm{~mm}$ from Loligosystems) tags in between adipose and dorsal fins. Fish were anesthetized by using MS-222 before the PIT tagging to reduce stressing the fish. At the same time, the total length and weight of the fish were measured. After the recovery period, fish were randomly allocated into six replicate tanks (163 l, flow-through), where both the infected and control fish were allocated in each tank proportionately, the total number of fish $\operatorname{tank}^{-1}$ varying from 45 to 69 . Moreover, two different levels of feeding regimes were applied so that three tanks (Tank 13, 14 and 15; high food group) were fed with $60 \mathrm{~g}$ and the remaining three tanks (Tank 18, 19 and 20; low food group) were fed with $36 \mathrm{~g}$ (60\% of the high food group) of commercial food pellets tank $\mathrm{k}^{-1}$ daily, except for Sunday. Amount of feed was constant and below ad libitum throughout the experiment. Total numbers of control and infected fish were 160 and 159, respectively. Total numbers of individuals in low food and high-food groups were 175 and 144, respectively. After the initial size, measurement during the PIT tagging in mid-September ( 2 weeks post-infection), later fish were anesthetized and measured on $21 \mathrm{st}$ November 2015 (12 weeks), 19th March 2016 (29 weeks), 20th May 2016 (38 weeks) and 6th July 2016 (45 weeks post-infection). 
The tanks were monitored daily, starting from the infection with $M$. margaritifera glochidia, for wellbeing and survival of fish. Dead or moribund fish were removed and recorded. These data indicated that most of the mortality of fish occurred during the first monitoring period, September-November 2015, while there was no mortality among any of the fish from March 2016 to the end of the experiment in July 2016. Total mortality during the experiment from September 2015 to July 2016 was $19 \%$ and $16 \%$ for glochidiainfected and control fish, respectively. Further, the tank-specific difference in instantaneous total mortality $[Z=-\ln$ (survival)] between infected and control fish ( $t$ test, $P=0.68$ ) or between high- and lowfeeding ( $t$ test, $P=0.21$ ) was not significant. Thus, differences in mortality between treatments do not bias the distribution of results, e.g. by encoring the observations with the strongest effects of certain treatment on growth and eventually to survival.

Three to four fish were randomly netted and killed to check entire gills of fish microscopically for the intensity of infection (= mean number of glochidia per infected fish), at each measurement occasion except for November 2015. Mean \pm SE intensity of infection (with mean length $(\mathrm{mm}) \pm \mathrm{SE}$ and number of fish studied in parentheses) in September 2015, March 2016, May 2016 and July 2016 was $7889 \pm 390$ $(167.67 \pm 2.96, n=3), 5473 \pm 445(169.11 \pm 3.60$, $n=18), 5202 \pm 804(197.33 \pm 18.89, n=3)$ and $3125 \pm 566(206.0 \pm 12.29, n=4)$ glochidia fish $^{-1}$. In the March 2016, measurement occasion, three glochidia-infected fish were examined from each of the high food and the low food tanks ( 3 fish $\times 3$ tanks $\times 2$ food treatments $=18$ fish). From this sampling, it was possible to compare the intensity of infection and size (growth) of glochidia between high and low food treatments, as 25 randomly chosen glochidia fish ${ }^{-1}$ were measured microscopically for length. To study the number and size of glochidia, fish individual-specific averages were first calculated. Then, those individual-specific values were used to calculate the mean tank-specific values (over the three fish individuals). Tank-specific mean intensity of infection and size of glochidia values were then used in analysis of covariance (ANCOVA) where tank was the statistical unit, feeding regime (low, high) was a fixed factor and the tank-specific average initial weight of fish was used as the covariate. The initial weight of fish, measured in September, 2 weeks after exposure to glochidia, was used as the covariate because the number of glochidia attached to fish depends on the size of fish at the time of infection, a higher number of glochidia being able to attach to larger fish (Thomas et al., 2014).

After May 2016, monitoring of growth was terminated in two tanks - one from the high food treatment (Tank 13) and one from the low food treatment (Tank 18), because the fish were used for collection of juvenile mussels for another study. Therefore, the complete growth data for all six tanks were available for three periods (1) September-November 2015, (2) November 2015-March 2016 and (3) March-May 2016.

During the experiment, water temperature varied from a maximum of $15.3^{\circ} \mathrm{C}$ in mid-September 2015 to a minimum of $1.1^{\circ} \mathrm{C}$ in mid-March 2016. Average temperatures during the periods (1) SeptemberNovember 2015, (2) November 2015-March 2016, (3) March-May 2016 and (4) May-July 2016 were 9.3, 2.8, 3.7 and $10.4^{\circ} \mathrm{C}$, respectively.

The specific growth rate $(G)$ of fish was calculated for each individual $(x)$ of fish and period $(P)$ by

$G_{x, P}=100 \ln \left(W_{x, P, E} / W_{x, P, B}\right) / t_{P}$

where $W$ is fresh weight of individual, $E$ is end of period, $B$ is beginning of period and $t_{P}$ is length of period in days.

The response variable was the tank $(T)$ and period $(P)$ specific difference $(D)$ of the average of specific growth rate between non-infected (control $=C$ ) and infected $(I)$ individuals

$D_{T, P}=\bar{G}_{T, P, C}-\bar{G}_{T, P, I}$

The difference in specific growth rate between control and infected fish was calculated for the three periods (1) September-November 2015; (2) November 2015-March 2016; (3) March-May 2016 between consecutive measurement occasions as well as for the whole period from September 2015 to May 2016. To take into account the fact that the growth of an individual can depend on its initial size, all G-values were corrected for the effect of initial weight at the beginning of the period and all statistics produced for those calibrated values. However, the results were not affected by this calibration and therefore only the noncalibrated results are shown here. 
As the daily amount of food issued within the tank was kept constant throughout the experiment, a rough index of relative daily feeding per biomass unit (FUB) was calculated for each tank and period. First, the average biomass of fish $(B)$ for every tank and period was estimated by simple linear interpolation

$\underline{B}_{T, P}=\left(B_{T, P, B}+B_{T, P, E}\right) / 2$

Then, this was scaled relative (\%) to the minimum average biomass of all tanks and periods (Tank 13, Period 1) and feeding regime (FR)

$F U B_{T, P}=100 F R_{T} \min \left(\underline{B}_{T, P}\right) / \underline{B}_{T, P}$

where $\mathrm{FR}_{T}=100 \%$ for Tanks 13, 14 and 15 and $60 \%$ for Tanks 18, 19 and 20.

The collection of $M$. margaritifera glochidia was performed with license POPELY/513/07.01/2011 from the North Ostrobothnia regional Centre for Economic Development, Transport and the Environment (Oulu, Finland). Permission to conduct the experiment with fish, license ESAVI/10184/ 04.10.07/2014, was granted by the Animal Experiment Board of Finland (regional administration of Southern Finland).

\section{Results}

The body weight of fish increased over the course of the 45 weeks (10 months) experiment, both in glochidia-infected and control fish, and in low and high food treatments (Fig. 1).

The tank-specific difference in average specific growth rate between control and infected individuals $\left(D_{T, P}\right.$ Eq. 2) was greater than 0 for every period separately as well as for the whole experiment $(P<0.006)$ (Table 1; Fig. 2). Thus, the negative effect of M. margaritifera glochidia on the growth of brown trout was evident and was already observed by the end of the first monitoring period (SeptemberNovember). Although the tank-specific average specific growth rate was positively associated with the feeding regime (low/high food) (Fig. 2), the feeding regime or period had no effect on the difference in the growth between control and glochidia-infected fish (repeated measure ANOVA, $P>0.4$ ). On average, the proportional increase in weight for control

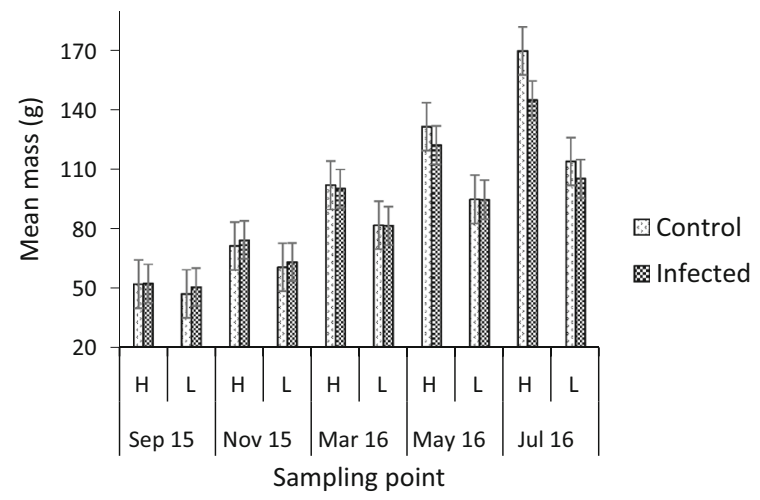

Fig. 1 Mean ( \pm SE) mass of control and infected brown trout in three replicate tanks of high $(\mathrm{H})$ and three replicate tanks low (L) food treatments in five measurement occasions after the infection with $M$. margaritifera glochidia on 31th of August 2015; 12th of September 2015 (Sep 15), 21st of November 2015 (Nov 15), 19th of March 2016 (Mar 16), 20th of May 2016 (May 16) and 6th of July 2016 (July 16)

individuals was $11 \%\left(=\mathrm{e}^{0.106}-1\right)$ higher than that for infected individuals during the experiment.

Neither the tank-specific mean number nor size of glochidia in March 2016 was affected by the covariate, initial weight of fish (ANOVA, $P>0.175$ ). However, whilst the size of glochidia was not affected by the feeding regime (ANOVA, $P=0.341$ ), there was a feeding-effect on the number of glochidia with risk level $P=0.057$ (ANOVA); a tendency was observed for higher number of glochidia in high food treatment, as the tank-specific, fish weight-adjusted mean $\pm \mathrm{SE}$ was $5939 \pm 218$ and $5007 \pm 218$ glochidia fish $^{-1}$ in high food and low food groups, respectively.

\section{Discussion}

As hypothesized, M. margaritifera glochidia infection reduced the growth of the fish host, brown trout, causing an $11 \%$ reduction in the proportional increase in weight during the 45 -week experiment. This implies a parasitic nature of $M$. margaritifera glochidia. Results from this study, together with those by Treasurer et al. (2006) and Ooue et al. (2017), provide clear evidence for an adverse effect of glochidia of Margaritifera mussels on the growth of their fish hosts. Thus, freshwater mussels - at least those having a long parasitic period-can negatively affect the growth rate of their fish host. Negative growth-effect of M. margaritifera was evident by the end of the first 
Table 1 The tank-specific difference in average specific growth rate between control and Margaritifera glochidiainfected brown trout $\left(D_{T, P}\right.$ Eq. 2$)$ by monitoring periods (Period 1: September-November 2015; 2: November 2015-
March 2016; 3: March-May 2016) and for the whole monitoring, in high food $\left(60 \mathrm{~g} \mathrm{tank}^{-1} \mathrm{day}^{-1}\right)$ and low food $\left(36 \mathrm{~g} \mathrm{tank}^{-1} \mathrm{day}^{-1}\right)$ treatments

\begin{tabular}{|c|c|c|c|c|c|}
\hline \multirow[t]{2}{*}{ Tank } & \multirow[t]{2}{*}{ Feeding } & \multicolumn{4}{|c|}{ Difference for period } \\
\hline & & 1 & 2 & 3 & Whole monitoring \\
\hline 13 & High food & -0.019 & 0.048 & 0.073 & 0.048 \\
\hline 14 & High food & 0.064 & 0.030 & 0.059 & 0.163 \\
\hline 15 & High food & 0.068 & 0.056 & 0.030 & 0.156 \\
\hline 18 & Low food & 0.026 & 0.038 & 0.039 & 0.055 \\
\hline 19 & Low food & -0.008 & 0.034 & 0.069 & 0.066 \\
\hline 20 & Low food & 0.085 & 0.089 & 0.077 & 0.150 \\
\hline Average & & 0.036 & 0.049 & 0.058 & 0.106 \\
\hline SE & & 0.018 & 0.009 & 0.008 & 0.022 \\
\hline$P$ & & $<0.094$ & 0.003 & 0.001 & 0.006 \\
\hline
\end{tabular}

Average difference, standard error (SE) and the $P$ value for the hypothesis that the average difference $>0$ are also given

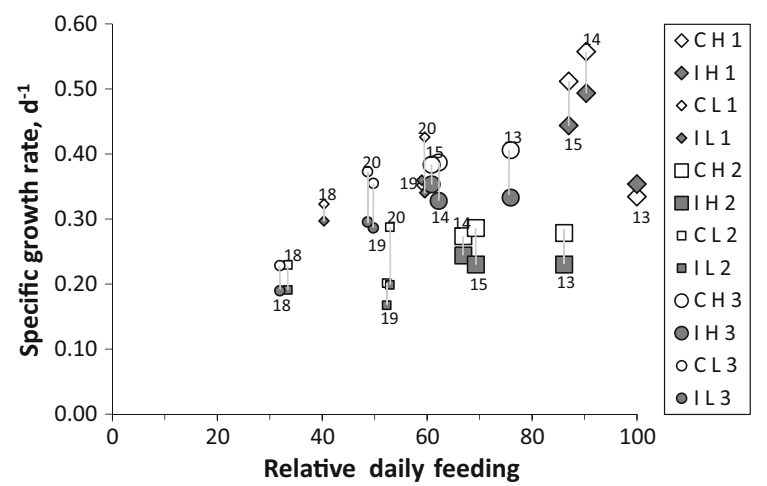

Fig. 2 The tank-specific average of specific growth rate $\left(G_{x, P}\right.$, Eq. 1) for control (C; open symbols) and infected (I; gray-filled symbols) fish in relation to feeding regime ( $H$ high food, large symbols; $L$ low food, small symbols). The numbers 1,2 and 3 (in figure legend and the symbols diamond, square and circle, respectively) refer to monitoring periods (1, SeptemberNovember 2015; 2, November 2015-March 2016; 3, MarchMay 2016). The vertical bars indicate the difference between control and infected individuals within a tank. The numbers refer to different tanks, 13-15 being high food tanks and 18-20 being low food tanks

monitoring period, suggesting that the growth impairment began upon infection of fish. Indeed, it is not surprising that mussel species that attach to fish for periods up to 11 months and that grow remarkably in size during that time (Hastie \& Young, 2001; Salonen \& Taskinen, 2017; present study), intakes nutrients from the host (Denic et al., 2015), causes respiratory burden and damage to gills (Taeubert \& Geist, 2013;
Thomas et al., 2014) and may impair feeding efficiency (Österling et al., 2014) of fish host.

The observed negative growth effect of M. margaritifera glochidia on the growth of fish host could be at least partly attributed to the respiratory burden caused by glochidia (Taeubert \& Geist, 2013; Thomas et al., 2014). Inhibition of respiration reduces the capacity of oxygen transportation to the muscle, which reduces nutrient intake due to the reduced anaerobic metabolism. Moreover, M. margaritifera glochidia induce acquired immunity response in fish (Chowdhury et al., 2017) that is presumably energetically costly, and glochidiosis, in general, can incur an energetic cost in fish host (Slavik et al., 2017) as well as increase the $\mathrm{k}+$ and $\mathrm{Cl}-$ concentrations in fish (Treasurer v Turnbull, 2000; Douda et al., 2017a).

Adverse effects of parasites on a host are usually density dependent. For example, a negative effect of M. margaritifera glochidia on critical swimming speed of brown trout, in an experiment conducted with similar sized fish as in the present study, increased with the intensity of infection and was evident only when exceeded 10,000 glochidia per host (Taeubert \& Geist, 2013). The initial mean number of glochidia fish ${ }^{-1}$ in our study was almost 8000 and numbers remained high at the end of the experiment in July 2016, with over 3000 glochidia fish $^{-1}$. In contemporary natural populations, mean intensity of M. margaritifera infection in salmonids only rarely exceeds 1000 glochidia fish ${ }^{-1}$ (Young \& Williams, 
1984; Cunjak \& McGladdery, 1991; Hastie \& Young, 2001; Salonen \& Taskinen, 2017). Thus, the number of glochidia in our study was higher than one would expect to see in natural conditions. Yet, it is possible that a negative growth effect, although less prominent, of M. margaritifera glochidia on the fish host would also exist with a lower intensity of infection, but at least for studying artificial restocking of mussels with intensively infested fish with the high numbers of glochidia used here are justified and the growthinfluence confirmed.

Feeding regime of fish host did not affect the level of growth-reduction induced by $M$. margaritifera glochidia on fish. Applied feeding regime included a constant amount of feed throughout the experiment, 60 and $36 \mathrm{~g} \mathrm{tank}^{-1}$ day $^{-1}$ in high and low food treatment, respectively. As fish grew, the relative feeding rate, in relation to the size of fish, decreased in both groups towards the end of the experiment. This may have intensified the competition for food and caused a shortage of food in the high food group. In spite of this, an observed difference in the specific growth rate between glochidia-infected and control fish existed throughout the experiment, whilst, the study period had no significant effect on the difference in growth between glochidia-infected and control fish. This indicates that there is no observable interaction between feeding rate and the negative growth-effect of $M$. margaritifera glochidia.

In a study conducted with Atlantic salmon, S. salar, and M. margaritifera (Treasurer et al., 2006), the weight of fish infected with glochidia was significantly lower than that of the control fish at 15 weeks post exposure, but not later. In the study performed with masu salmon, Oncorhynchus masou masou, and the freshwater pearl mussel M. laevis (Ooue et al., 2017), the weight of fish infected with glochidia was not reduced in the middle of the parasitic period but was significantly lower than that of the control fish after the parasitic period (70 d post infection). Mean initial intensity of infection in studies by Treasurer et al. (2006) and Ooue et al. (2017) were close to 1400 and 800 glochidia fish $^{-1}$, respectively. These are clearly lower values than in the present study, which may partly contribute to the similar, but less obvious growth-effects of Margaritifera glochidia observed in those studies. Therapeutic treatment of fish at week 15 , reducing high glochidia intensity, may have also influenced the disappearance of negative growth- effects after 15 weeks in the experiment by Treasurer et al. (2006).

Our results from March 2016 sampling did not indicate a relationship between the feeding of fish and growth of glochidia, but there appeared to be a trend for a higher intensity of $M$. margaritifera infection in the high food treatment than in the low food group. Thus, low feeding of fish may increase the number of glochidia detached prematurely; if the initial infection intensity is assumed to equal in high and low food groups. However, this result should be considered cautiously and urges further studies. The sample size was low, and our experiment was not precisely designed to study the effect of feeding regime on the growth or number of glochidia.

Ideally, the fish should be kept in individual containers to enable the use of each fish as an independent observational unit in a growth experiment. However, individual fish could not be used as an independent sampling unit in this experiment because the individuals in one tank can interfere with each other e.g. by food competition and dominance hierarchy between different sized individuals. If the control group grows faster and the food competition/hierarchy favors largest individuals, then the difference in growth between these groups (control vs. infected) can be larger than that in the case where the groups were kept separate. The results, therefore, may bias (exaggerate) the negative main effect of infection. Further, even in a separated group of only control or only infected individuals, there might be competition/ hierarchy-based differences between individuals, which could at least affect the variance in growth between individuals if not the average. Thus, to measure the effect of parasitism on growth without bias, the individuals should be kept in separate tanks with controlled feeding and their parasite number should be monitored. It was not possible to keep the fish individually but we formed mixed, replicated groups of PIT-tagged fish. Fish used in this experiment were collected from the same age group and similar size to minimise the bias. In addition, having infected and control fish in the same tank ensured equivalent conditions for both groups in terms of temperature, oxygen, and water flow. The present design also enabled the establishment of natural social interactions between (and within) infected and control fish. It was also important that there was no difference in the mortality of fish between infected and control 
individuals during the experiment-differential mortality cannot thus affect the growth results.

To avoid growth rate biasness, equal sized $1+$ year old fish were used for this experiment. However, in the first sampling period, the infected fish had a slightly higher mean mass than the control fish both in the high and low food treatment (Fig. 2). This could have contributed to their lower specific growth rate since the larger the initial size the less potential there is for growth, in principle, and the higher the initial biomass, the less feeding per weight unit with a fixed feeding rate. Nevertheless, the slightly larger size at the beginning of the experiment does not explain the clearly observed lower size of the infected fish, as compared to the control individuals, at the end of the experiment (Fig. 2).

Freshwater mussels are in decline all over the world (Lydeard et al., 2004; Bogan, 2008; Geist, 2010) including $M$. margaritifera that has become widely extinct in central Europe during the last century (Bauer, 1986; Buddensiek, 1995) although the species used to be abundant previously in European salmonid fish rivers (Young \& Williams, 1984; Cosgrove et al., 2000; Geist, 2010). 40\% of the freshwater bivalves are near threatened, threatened or extinct worldwide Lopes-Lima et al. (2018) whereas $75 \%$ (12 out 16, enlisted in IUCN Red List) of European freshwater mussel species as threatened or near threatened (Lopes-Lima et al., 2017). From a conservation point of view, the observed growth-effect of M. margaritifera on the salmonid host can be regarded as a disadvantage. If glochidia-infected stockings are used to strengthen or restore $M$. margaritifera populations (see Wellmann, 1943; Buddensiek, 1995; Geist et al., 2006; Thomas et al., 2010; Sousa et al., $2013,2015,2018)$, it would be attractive to encourage landowners, fishery managers, fishing right owners' associations and salmonid conservation programmes to use glochidia-infected juvenile Salmo spp. in their stockings. However, the observed $11 \%$ reduction in the growth of brown trout due to $M$. margaritifera glochidia may not be an obstacle for the fish farming industry to participate in the production of glochidiainfected brown trout stockings, especially when the survival effect was also not there. In some $M$. margaritifera regions in northern Fennoscandia, such stockings are being conducted on a regular basis anyway, so there is perhaps no reason to not use stock infected with $M$. margaritifera glochidia. An advantage of this method would be that the declining salmonid host populations would strengthen, as the low density of fish host can be an important limiting factor for M. margaritifera recruitment e.g. in northern European rivers (Arvidsson et al., 2012; see also Bauer, 1988). Moreover, negligible mortality due to the glochidiosis found in this study would certainly inspire fish farmers to participate in stocking glochidia-inoculated salmonid fish instead of stocking glochidia-free salmonid. Another conservation implication of this study could be that low feeding of fish may decrease the number of glochidia during the parasitic period. If this is the case, low feeding of fish could expose the glochidia to detach prematurely, but this requires further studies. This would lead to a lower yield of M. margaritifera juveniles in captive breeding. Moreover, infection elicits changes in the metabolic priorities within the host mainly associated with immunity, which may suppress food intake and increase the risk of predation due to the weakling (Lochmiller \& Deerenberg, 2000). Therefore, the decision of the intensity of infection for stocking glochidia-inoculated salmonid into the river should be taken skeptically as there is food limitation. For the welfare of fish, the infection intensity used in this study (138 \pm 3 glochidia $\mathrm{g}^{-1}$ of fish) is realistic for the juvenile culture in the laboratory in the line of findings by Taeubert and Geist 2013 (up to 300 glochidia $\mathrm{g}^{-1}$ of fish). However, for stocking glochidiainoculated salmonid fish into nature Taeubert and Geist (2013) suggested up to 5-100 glochidia $g^{-1}$ of fish.

To conclude, we obtained unambiguous evidence for negative growth-effect of freshwater mussel glochidia on the fish host, thereby supporting the view of the parasitic nature of glochidia. Together with earlier results (Treasurer et al., 2006; Ooue et al., 2017), this suggests that at least mussel species with a long parasitic period can noticeably impair the growth of their fish hosts. Results from this study add to the list of negative effects of $M$. margaritifera on its salmonid host (Treasurer \& Turnbull, 2000; Taeubert \& Geist, 2013; Österling et al., 2014; Thomas et al., 2014; Filipsson et al., 2016, 2017). However, as the growth-effect on brown trout can be expected to be low in natural infection intensities of less than 1000 glochidia fish ${ }^{-1}$, this result should encourage testing the introduction of artificially infected fish, (Wellmann, 1943; Buddensiek, 1995; Geist et al., 2006; 
Thomas et al., 2010; Sousa et al., 2013, 2015, 2018) as a conservation measure of this endangered species. Finally, together with the observed lack of mortality effects, this may turn public opinion favorable for $M$. margaritifera conservation even if the salmonid host population is important for commercial or recreational fishing.

Acknowledgements Open access funding provided by University of Jyväskylä (JYU). We are thankful to Juhani Pirhonen, Apurba Majumder, Mikhail Gopko, Tapani Säkkinen and staff of the Konnevesi Research Station for their contribution. We are also thankful to Rhian Thomas for commenting and checking the language of this manuscript. This study was financed by and Maj and Tor Nessling Foundation and Raija and Ossi Tuuliainen Foundation.

Open Access This article is distributed under the terms of the Creative Commons Attribution 4.0 International License (http:// creativecommons.org/licenses/by/4.0/), which permits unrestricted use, distribution, and reproduction in any medium, provided you give appropriate credit to the original author(s) and the source, provide a link to the Creative Commons license, and indicate if changes were made.

\section{References}

Arvidsson, B. L., J. Karlsson \& M. E. Österling, 2012. Recruitment of the threatened mussel Margaritifera margaritifera in relation to mussel population size, mussel density and host density. Aquatic Conservation: Marine and Freshwater Ecosystems 22: 526-532.

Bauer, G., 1986. The status of the freshwater pearl mussel Margaritifera margaritifera $\mathrm{L}$. in the South of its European range. Biological Conservation 38: 1-9.

Bauer, G., 1988. Threats to the freshwater pearl mussel Margaritifera margaritifera L. in Central Europe. Biological Conservation 45: 239-253.

Bauer, G. \& C. Vogel, 1987. The parasitic stage of the freshwater pearl mussel (Margaritifera margaritifera L.) I. Host response to Glochidiosis. Archiv fr Hydrobiologie 76: 393-402.

Bogan, A. E., 2008. Global diversity of freshwater mussels (Mollusca, Bivalvia) in freshwater. Hydrobiologia 595: 139-147.

Buddensiek, V., 1995. The culture of juvenile freshwater pearl mussels Margaritifera margaritifera L. in cages: a contribution to conservation programmes and the knowledge of habitat requirements. Biological Conservation 74: 33-44.

Chowdhury, M. M. R., J. K. Salonen, T. J. Marjomäki \& J. Taskinen, 2017. Interaction between the endangered freshwater pearl mussel Margaritifera margaritifera, the duck mussel Anodonta anatina and the fish host (Salmo): acquired and cross-immunity. Hydrobiologia 810: 273-281.
Cosgrove, P. J., M. R. Young, L. C. Hastie, M. Gaywood \& P. J. Boon, 2000. The status of the freshwater pearl mussel Margaritifera margaritifera Linn. in Scotland. Aquatic Conservation: Marine and Freshwater Ecosystems 10: 197-208.

Cunjak, R. A. \& S. E. McGladdery, 1991. The parasite-host relationship of glochidia (Mollusca: Margaritiferidae) on the gills of young-of-the-year Atlantic salmon (Salmo salar). Canadian Journal of Zoology 69: 353-358.

Denic, M., J.-E. Taeubert \& J. Geist, 2015. Trophic relationships between the larvae of two freshwater mussels and their fish hosts. Invertebrate Biology 134: 129-135.

Douda, K., J. Velîšek, J. Kolářová, K. Rylková, O. Slavík, P. Horký \& I. Langrová, 2017a. Direct impact of invasive bivalve (Sinanodonta woodiana) parasitism on freshwater fish physiology: evidence and implications. Biological Invasions 19(3): 989-999.

Douda, K., H. Z. Liu, D. Yu, R. Rouchet, F. Liu, Q. Tang, C. Methling, C. Smith \& M. Reichard, 2017b. The role of local adaptation in shaping fish-mussel coevolution. Freshwater Biology 62: 1858-1868.

Eybe, T., F. Thielen, T. Bohn \& B. Sures, 2015. Influence of the excystment time on the breeding success of juvenile freshwater pearl mussels (Margaritifera margaritifera). Aquatic Conservation: Marine and Freshwater Ecosystems 25: 21-30.

Filipsson, K., T. Petersson, J. Höjesjö, J. J. Piccolo, J. Näslund, N. Wengström \& E. M. Österling, 2016. Heavy loads of parasitic freshwater pearl mussel (Margaritifera margaritifera L.) larvae impair foraging, activity and dominance performance in juvenile brown trout (Salmo trutta L.). Ecology of Freshwater Fish 27: 70-77.

Filipsson, K., J. Brijs, J. Näslund, N. Wengström, M. Adamsson, L. Závorka, E. M. Österling \& J. Höjesjö, 2017. Encystment of parasitic freshwater pearl mussel (Margaritifera margaritifera) larvae coincides with increased metabolic rate and haematocrit in juvenile brown trout (Salmo trutta). Parasitology Research 116: 1353-1360.

Fritts, M. W., A. K. Fritts, S. A. Carleton \& R. B. Bringolf, 2013. Shifts in stable-isotope signatures confirm parasitic relationship of freshwater mussel glochidia attached to host fish. Journal of Molluscan Studies 79: 163-167.

Geist, J., 2010. Strategies for the conservation of endangered freshwater pearl mussels (Margaritifera margaritifera L.): a synthesis of conservation genetics and ecology. Hydrobiologia 644: 69-88.

Geist, J., M. Porkka \& R. Kuehn, 2006. The status of host fish populations and fish species richness in European freshwater pearl mussel (Margaritifera margaritifera) streams. Aquatic Conservation: Marine and Freshwater Ecosystems 16: 251-266.

Gum, B., M. Lange \& J. Geist, 2011. A critical reflection on the success of rearing and culturing juvenile freshwater mussels with a focus on the endangered freshwater pearl mussel (Margatitifera margaritifra L.). Aquatic Conservation: Marine and Freshwater Ecosystems 21: 743-751.

Hastie, L. C. \& M. R. Young, 2001. Freshwater pearl mussel (Margaritifera margaritifera) glochidiosis in wild and farmed salmonid stocks in Scotland. Hydrobiologia 445: 109-119. 
Horky, P., K. Douda, M. Maciak, L. Zavorka \& O. Slavik, 2014. Parasite-induced alterations of host behaviour in a riverine fish: the effects of glochidia on host dispersal. Freshwater Biology 59: 1452-1461.

Kekäläinen, J., J. Pirhonen \& J. Taskinen, 2014. Do highly ornamented and less parasitized males have high quality sperm? - an experimental test for parasite-induced reproductive trade-offs in European minnow (Phoxinus phoxinus). Ecology and Evolution 4: 4237-4246.

Lochmiller, R. L. \& C. Deerenberg, 2000. Trade-offs in evolutionary immunology: just what is the cost of immunity? Oikos 88: 87-98.

Lopes-Lima, M., R. Sousa, J. Geist, D. C. Aldridge, R. Araujo, J. Bergengren, Y. Bespalaya, E. Bódis, L. Burlakova, D. Van Damme, K. Douda, E. Froufe, D. Georgiev, C. Gumpinger, A. Karatayev, Ü. Kebapçi, I. Killeen, J. Lajtner, B. M. Larsen, R. Lauceri, A. Legakis, S. Lois, S. Lundberg, E. Moorkens, G. Motte, K.-O. Nagel, P. Ondina, A. Outeiro, M. Paunovic, V. Prié, T. von Proschwitz, N. Riccardi, M. Rudzīte, M. Rudzītis, C. Scheder, M. Seddon, H. Şereflişan, V. Simić, S. Sokolova, K. Stoeckl, J. Taskinen, A. Teixeira, F. Thielen, T. Trichkova, S. Varandas, H. Vicentini, K. Zajac, T. Zajac \& S. Zogaris, 2017. Conservation status of freshwater mussels in Europe: state of the art and future challenges. Biological Reviews 92: 572-607.

Lopes-Lima, M., L. E. Burlakova, A. Y. Karatayev, K. Mehler, M. Seddon \& R. Sousa, 2018. Conservation of freshwater bivalves at the global scale: diversity, threats and research needs. Hydrobiologia. https://doi.org/10.1007/s10750017-3486-7.

Lydeard, C., R. H. Cowie, W. F. Ponder, A. E. Bogan, P. Bouchet, S. A. Clark, K. S. Cummings, J. F. Terrence, O. Gargominy, D. G. Herbert, R. Hershler, K. E. Perez, B. Roth, M. Seddon, E. E. Strong \& F. G. Thompson, 2004. The global decline of nonmarine mollusks. BioScience 54: 321-330.

Modesto, V., M. Ilarri, A. T. Souza, M. Lopes-Lima, K. Douda, M. Clavero \& R. Sousa, 2018. Fish and mussels: importance of fish for freshwater mussel conservation. Fish and Fisheries 19: 244-259.

Moorkens, E. A., 2018. Short-term breeding: releasing postparasitic juvenile Margaritifera into ideal small-scale receptor sites: a new technique for the augmentation of declining populations. Hydrobiologia 810: 145-155.

Ooue, K., A. Terui, H. Urabe \& F. Nakamura, 2017. A delayed effect of the aquatic parasite Margaritifera laevis on the growth of the salmonid host fish Oncorhynchus masou masou. Limnology 18: 345-351.

Österling, E. M., J. Ferm \& J. J. Piccolo, 2014. Parasitic freshwater pearl mussel larvae (Margaritifera margaritifera L.) reduce the drift-feeding rate of juvenile brown trout (Salmo trutta L.). Environmental Biology of Fishes 97: 543-549.

Oulasvirta, P., J. Leinikki \& J. Syväranta, 2017. Freshwater pearl mussel in Finland - current status and future prospects. Biology Bulletin 44: 81-91.

Rogers-Lowery, C. L., R. V. Dimock \& R. E. Kuhn, 2007. Antibody response of bluegill sunfish during development of acquired resistance against the larvae of the freshwater mussel Utterbackia imbecillis. Developmental \& Comparative Immunology 31: 143-155.
Salonen, J. K. \& J. Taskinen, 2017. Electrofishing as a new method to search for unknown populations of the endangered freshwater pearl mussel Margaritifera margaritifera. Aquatic Conservation: Marine and Freshwater Ecosystems 27: 115-127.

Salonen, J. K., T. J. Marjomäki \& J. Taskinen, 2016. An alien fish threatens an endangered parasitic bivalve: the relationship between brook trout (Salvelinus fontinalis) and freshwater pearl mussel (Margaritifera margaritifera) in northern Europe. Aquatic Conservation: Marine and Freshwater Ecosystems 26: 1130-1144.

Salonen, J. K., P.-L. Luhta, E. Moilanen, P. Oulasvirta, J. Turunen \& J. Taskinen, 2017. Atlantic salmon (Salmo salar) and brown trout (Salmo trutta) differ in their suitability as a host for the endangered freshwater pearl mussel (Margaritifera margaritifera) in northern Fennoscandian rivers. Freshwater Biology 62: 1346-1358.

Slavik, O., P. Horky, K. Douda, J. Velisek, J. Kolarova \& P. Lepic, 2017. Parasite-induced increases in the energy costs of movement of host freshwater fish. Physiology and Behavior 171: 127-134.

Sousa, R., A. Amorim, C. Sobral, E. Froufe, S. Varandas, A. Teixeira \& M. Lopes-Lima, 2013. Ecological status of a Margaritifera margaritifera (Linnaeus, 1758) population at the southern edge of its distribution (River Paiva, Portugal). Environmental Management 52: 1230-1238.

Sousa, R., A. Amorim, C. Sobral, E. Froufe, S. Varandas, A. Teixeira \& M. Lopes-Lima, 2015. Conservation status of the freshwater pearl mussel Margaritifera margaritifera in Portugal. Limnologica 50: 4-10.

Sousa, R., A. Ferreira, F. Carvalho, M. Lopes-Lima, S. Varandas \& A. Teixeira, 2018. Die-offs of the endangered pearl mussel Margaritifera margaritifera during an extreme drought. Aquatic Conservation: Marine and Freshwater Ecosystems 28: 1244-1248.

Taeubert, J. E. \& J. Geist, 2013. Critical swimming speed of brown trout (Salmo trutta) infected with freshwater pearl mussel (Margaritifera margaritifera) glochidia and implications for artificial breeding of an endangered mussel species. Parasitology Research 112: 1607-1613.

Terui, A., K. Ooue, H. Urabe \& F. Nakamura, 2017. Parasite infection induces size-dependent host dispersal: consequences for parasite persistence. Proceedings of the Royal Society B: Biological Sciences 284(1866): 20171491. https://doi.org/10.1098/rspb.2017.1491.

Thomas, G. R., J. Taylor \& C. Garcia de Leaniz, 2010. Captive breeding of the endangered Freshwater Pearl Mussel, Margaritifera margaritifera. Endangered Species Research 12: 1-9.

Thomas, G. R., J. Taylor \& C. Garcia de Leaniz, 2014. Does the parasitic freshwater pearl mussel M. margaritifera harm its host? Hydrobiologia 735: 191-201.

Treasurer, J. W. \& T. Turnbull, 2000. The pathology and seawater performance of farmed Atlantic salmon infected with glochidia of Margaritifera margaritifera. Journal of Fish Biology 57: 858-866.

Treasurer, J. W., L. C. Hastie, D. Hunter, F. Duncan \& C. M. Treasurer, 2006. Effects of (Margaritifera margaritifera) glochidial infection on performance of tank-reared Atlantic salmon (Salmo salar). Aquaculture 256: 74-79. 
Wellmann, G., 1943. Fischinfektionen mit Glochidien der Margaritana margaritifera. Z. Fischerei 41: 385-390.

Young, M. \& J. Williams, 1984. The reproductive biology of the freshwater pearl mussel Margaritifera margaritifera in Scotland I. Field studies. Archiv fr Hydrobiologie 99: 405-422.

Ziuganov, V. V., 2005. A long-lived parasite extending the host life span: the pearl mussel Margaritifera margaritifera elongates host life by turns out the program of accelerated senescence in salmon Salmo salar. Doklady Biological Science 403: 291-294.

Publisher's Note Springer Nature remains neutral with regard to jurisdictional claims in published maps and institutional affiliations. 